\title{
Chewing on It Can Chew You Up: Effects of Rumination on Triggered Displaced Aggression
}

\author{
Brad J. Bushman \\ University of Michigan \\ William C. Pedersen \\ California State University, Long Beach
}

\author{
Angelica M. Bonacci \\ Iowa State University
}

\begin{abstract}
Ruminating about a provocation increases the likelihood of displaced aggression following a minor annoyance (trigger). In Study 1, provoked participants who ruminated for 25 min were more aggressive toward a fumbling confederate than were distracted participants. Provocation-induced negative affect was positively related to aggression but only among those who ruminated. Study 2 conceptually replicated Study 1 and also found that the more negatively people reacted to the trigger, the more likely the trigger was to increase displaced aggression. Study 3 replicated the findings of Studies 1 and 2 by using an 8-hr rumination period. All 3 studies suggest that ruminating about a provocation increases the likelihood that a minor triggering annoyance will increase displaced aggression.
\end{abstract}

Keywords: displaced aggression, rumination, triggering event

Frank arrives 15 min late to work for the 3rd day in a row. His angry boss gives him a stern reprimand, stating that the company has no place for lazy and unreliable workers. On the way to the cafeteria for his morning cup of coffee, Frank keeps thinking about the reprimand and how much he hates his boss. As he waits in line to pay, a coworker cuts in front of him. Frank angrily snaps at her and orders her to the end of the line in an outburst laced with obscenities.

Jill spent weeks preparing a presentation for her college class. After her presentation, her professor harshly criticizes her performance, stating that she was unprepared and disorganized. For the entire day, Jill silently fumes about her professor's critical remarks. When she returns to her apartment at the end of the day, Jill curses at her roommate for leaving dirty dishes in the sink.

Brad J. Bushman, Institute for Social Research, University of Michigan; Angelica M. Bonacci, Department of Psychology, Iowa State University; William C. Pedersen, Department of Psychology, California State University, Long Beach; Eduardo A. Vasquez and Norman Miller, Department of Psychology, University of Southern California.

Study 2 was conducted in partial fulfillment of Angelica M. Bonacci's master's degree requirements. Study 1 was supported by a grant to Norman Miller from the James H. Zumberge fund, University of Southern California. Preparation of this article was facilitated by National Institute on Alcohol Abuse and Alcoholism Grant R21-AA013343.

Correspondence concerning this article should be addressed to Brad J. Bushman, Institute for Social Research, University of Michigan, 426 Thompson Street, Ann Arbor, MI 48106, or to Norman Miller, Department of Psychology, University of Southern California, Los Angeles, CA 900891061. E-mail: bbushman@umich.edu or nmiller@usc.edu

\section{Displaced Aggression}

Aggression is behavior intended to harm another person. Aggression is direct when an individual is provoked and, in retaliation, inflicts harm against the provoker. Aggression is displaced when the target is innocent of any wrongdoing but is simply in the wrong place at the wrong time. Displaced aggression can occur when a person cannot aggress or is constrained from aggressing against a source of provocation. To aggress directly against the source of the initial provocation may be unfeasible because the source is unavailable (e.g., the provoker has left the situation) or because the source is an intangible entity (e.g., loud noise, foul odor, hot temperature). Fear of retaliation or punishment from the provocateur might also constrain direct aggression (Dollard, Doob, Miller, Mowrer, \& Sears, 1939). For example, if the provocateur is one's boss, as in the beginning scenario, then one might get fired for an aggressive response.

Apart from our own work with colleagues (Bushman \& Baumeister, 1998; Bushman, Baumeister, \& Stack, 1999; Pedersen, Gonzales, \& Miller, 2000), virtually no recent experimental research has examined displaced aggression. Moreover, content analysis of social psychology textbooks shows that contemporary social psychology has largely ignored this concept (MarcusNewhall, Pedersen, Carlson, \& Miller, 2000). Despite this apparent disinterest, meta-analytic results confirm that displaced aggression is alive and well (Marcus-Newhall et al., 2000). Displaced aggression is a reliable effect that is of moderate magnitude $\left(d_{+}=0.55\right.$; see Cohen, 1988).

\section{Triggered Displaced Aggression}

In the typical displaced-aggression research paradigm, participants are initially provoked and then allowed to aggress against an 
innocent third party. Such studies, however, do not capture all instances of displaced aggression. Often, the target of displaced aggression is not an innocent, nonprovoking individual. Rather, as illustrated by our opening anecdotes, the target emits a mildly annoying act, as when the coworker cut in line or the roommate left dirty dishes in the sink. The term triggered displaced aggression refers to such instances. Following an initial provocation, the target commits a minor provocation, the triggering event, which in turn prompts an aggressive response (Dollard, 1938). The initial provocation and the subsequent triggering event can synergistically combine to elicit a disjunctively augmented aggressive response toward the triggering target. By disjunctively augmented, we mean that the aggression directed toward the target exceeds that which is predicted by a tit-for-tat matching rule (Axelrod, 1984). That is, the aggression directed toward the target exceeds what is expected on the basis of the intensity of the triggering event or exceeds what is expected by adding the separate aggression-eliciting effects of the provocation and the triggering event (Miller \& Marcus-Newhall, 1997).

An important caveat is that the intensity of the triggering event must be minor in comparison with the initial provocation in order for such a synergistically interactive aggressive response to occur (Miller \& Marcus-Newhall, 1997; Pedersen et al., 2000; Vasquez, Denson, Pedersen, Stenstrom, \& Miller, 2005). Minor triggering events are more ambiguous with respect to provocation and intentionality than are strong ones (Vasquez et al., 2005). In the absence of the initial provocation, an individual might judge the triggering event as nonprovocative and unworthy of an aggressive retaliation. However, a strong initial provocation might prime individuals to experience triggering events as more intentional and provoking and deserving of an aggressive retaliation (Duncan, 1976; Higgins $\&$ King, 1981). If the triggering event does not produce an aggressive response in the absence of a strong initial provocation, then it must be relatively minor in comparison with the initial provocation.

One problem with the few initial studies on triggered displaced aggression is that the intensity of the triggering event was at least as strong as the intensity of the initial provocation (Pedersen et al., 2000). Consequently, the hypothesized interaction between provocation and trigger did not occur. However, two recent studies confirmed the moderating effect of a minor triggering event on displaced aggression (Pedersen et al., 2000). For example, in one of these studies, participants were either provoked or not provoked by an experimenter. Later, they interacted with a confederate who was either incompetent (trigger) or competent (no trigger). As expected, participants who were initially provoked displayed more displaced aggression in the presence of a triggering event than in its absence. The trigger had no effect on participants who were not provoked (see also Vasquez et al., 2005).

\section{Theoretical Model of Triggered Displaced Aggression}

Miller, Pedersen, Earleywine, and Pollack (2003) proposed a theoretical model of triggered displaced aggression that is based, in part, on Berkowitz's $(1989,1990,1993)$ cognitive neoassociation model of aggression. Berkowitz posited that aggressive thoughts, emotions, and behavioral tendencies are linked together in an associative network. Aversive events (e.g., provocation) prompt negative affect. Negative affect, in turn, prompts two different reactions: fight tendencies, which are associatively linked with aggression, and flight tendencies, which are associatively linked with fear. If fight tendencies are activated, then aggressive thoughts, feelings, and behavioral tendencies are also activated because they are part of the same associative network. Similarly, thoughts, feelings, arousal levels, and behavioral intentions are interconnected in the general aggression model (GAM; Anderson \& Bushman, 2002). For example, angry feelings and increased arousal levels might bring to mind aggressive thoughts.

Ruminatively based displaced aggression describes acts of displaced aggression that occur long after the initial provocation. When the temporal gap between the initial provocation and the subsequent triggering event exceeds $20 \mathrm{~min}$, then displaced aggression is primarily a result of rumination. Miller et al. (2003) argued that ruminative processes maintain a cognitive representation of the subjective state generated by the initial provocation, even though the initial physiological arousal from that provocation has dissipated. Rumination facilitates displaced aggression because it maintains the aggression network activated by the initial provocation.

\section{Triggered Ruminative Aggression}

Rumination has been defined as self-focused attention toward one's thoughts and feelings (Lyubomirsky \& Nolen-Hoeksema, 1995). Rumination can also be defined more narrowly as provocation-focused thought. Ruminative thought can maintain angry feelings (Martin \& Tesser, 1989; Rusting \& NolenHoeksema, 1998). In previous research, the relationship between an initial provocation and subsequent displaced aggression was mediated by how angry people became after experiencing a triggering event (Pedersen et al., 2000). ${ }^{1}$ Among provoked participants, the triggering event generated angry feelings. These angry feelings, in turn, prompted an aggressive retaliation against the mildly annoying target. Among nonprovoked participants, the triggering event did not augment aggressive behavior. Recall our opening anecdote in which the college student who was harshly criticized by her professor and had ruminated about it during the car ride home subsequently cursed at her messy roommate when she got home. In parallel, any process that maintains an angry mood after an initial provocation, such as rumination, should increase triggered displaced aggression. Likewise, any process that distracts attention away from an angry mood should decrease triggered displaced aggression.

No prior study has examined whether ruminating about a provocation augments aggressive responding to a mildly annoying

\footnotetext{
${ }^{1}$ Reanalysis of Pedersen et al.'s (2000) data indicated that provoked participants became angrier after experiencing a triggering event than did nonprovoked participants. This finding held true in both Study $1, t(30)=1.98$, $p=.06$, and Study 2, $t(22)=2.23, p=.04$, despite differences in how the provocation and the trigger were operationally defined in the two studies.
} 
event that occurs long after an initial provocation. ${ }^{2}$ We propose that ruminating about a provocation will increase aggressive responding to a subsequent triggering event. We expected provoked individuals who were induced to ruminate for an extended period-namely, 25 and $20 \mathrm{~min}$ (Studies 1 and 2, respectively) or 8 hr (Study 3) - to exhibit more displaced aggression after a trigger than those not induced to ruminate.

How does rumination augment aggressive reaction to a triggering event? In keeping with Berkowitz's (1989, 1990, 1993) cognitive neoassociation model, which ascribes a key aggressioninstigating role to negative affect, our preceding discussion has emphasized cognitive representations of negative (angry) affect as a critical aggression-inducing component of rumination. By contrast, the GAM (Anderson \& Bushman, 2002) emphasizes physiological arousal, affect, attributions, and behavioral intentions as conceptually distinct factors, any or all of which can function independently to increase aggression. Thus, although rumination is necessarily cognitive, the GAM implies that it can consist of cognitive representations and elaborations of any or all four of these aggression-inducing antecedents: (a) arousal cognitionsawareness of one's prior physiological responses to the provocation, (b) affect cognitions - awareness of specific emotions felt at the time of the provocation, (c) attributions or interpretations concerning the provocateur's aggressive act-"he thought I was stupid," and (d) behavioral inclinations - thought about specific acts of harm that one wished one had bestowed on the provocateur. Extending the GAM, to the degree that rumination contains cognitive representations of any or all four of these factors, it will heighten sensitivity and reaction to a mild triggering event, thereby increasing aggressive responding to it.

Here, however, we cannot systematically explore such details concerning how rumination produces these effects, nor can we test the comparative validity of the neoassociationistic versus the GAM implications regarding the critical mediating components of rumination. Thus, although we do examine the aggressionmediating role of the rumination-induced augmentation of angry affect and angry attributions in response to the trigger, we do not examine the other types of cognitive representations that may be elicited during rumination (i.e., physiological arousal and behavioral intentions) and whose cognitive accessibility is seen by the GAM as also mediating aggression. Nor do we explore here the temporal positioning of their occurrence.

\section{Study 1}

In typical displaced-aggression paradigms, the temporal gap between provocation and the displaced-aggression opportunity rarely, if ever, exceeds $10 \mathrm{~min}$. Research suggests that without rumination, anger generally dissipates within $10 \mathrm{~min}$ (Fridhandler \& Averill, 1982; Tyson, 1998). The purpose of Study 1 was to test whether ruminating about a provocation beyond $10 \mathrm{~min}$ would increase the likelihood of triggered displaced aggression. In the presence of a triggering event, we expected displaced aggression to be higher for people induced to ruminate about the provocation than for those not induced to ruminate. In the absence of a triggering event, we expected little displaced aggression, regardless of whether people ruminated about the provocation. We also expected the anger produced by the provocation to increase dis- placed aggression but only among people who ruminated about the provocation.

\section{Method}

\section{Participants and Design}

Participants were 42 undergraduate students from the University of Southern California (29 women and 13 men) who received extra course credit for voluntarily serving in a 3 (rumination, distraction, positive mood) $\times 2$ (trigger, no trigger) between-subjects design.

\section{Procedure}

Participants were tested individually. They were told that the researchers were conducting a three-part study on various cognitive skills. The first part ostensibly investigated the effect of music on problem-solving ability. In reality, it served as the induction of provocation. Each participant received a list of 15 difficult anagrams (e.g., NVTNIMEREON unscrambled to spell ENVIRONMENT) and was told to solve all of them within 4 min. The participant listened to loud and distracting background music (viz., Stravinsky's Rites of Spring) while working on the anagrams. After $4 \mathrm{~min}$, the experimenter returned, turned off the music, took the anagram sheet (ostensibly to grade it), and gave the participant anagram scores from a sample of engineering students who manifestly performed quite well on the task. A few minutes later, the experimenter returned with the participant's test "score." He stated that the participant's score was below average as compared with the sample of engineering students. He said that the participant's performance was very poor and that the anagram portion of the experiment should be done over again. The experimenter then added, in an exasperated and irritated tone, that it would be a waste of his own time to repeat the test and that they should just proceed to the second part of the study. Pedersen et al. (2000, Study 1) have successfully used this procedure to induce provocation in previous research.

Participants were told that the second part of the study assessed imagination and creativity. They were randomly assigned to one of three groups: rumination, distraction, or positive mood. Participants in the rumination and distraction groups were given a packet with a phrase on each page. They were told to think about each phrase, spend 1 or 2 min writing any thoughts that came to mind on a pad of paper, and then move on to the next page of the packet and repeat this same process for $25 \mathrm{~min}$. They were told not to worry about spelling or grammar. In the rumination condition, the phrases were internally focused. To avoid making participants suspicious, the phrases did not mention specific emotions (e.g., anger). Examples included "what kind of a person you are," "why people treat you the way they do," and "how you interact with people." In the distraction group, the phrases were externally focused. Examples included "the layout of the local post office," "a double-decker bus driving down the street," and "clouds floating by in the sky." In previous research, judges rated both types of phrases as affectively neutral (Rusting \& Nolen-Hoeksema, 1998). In the positive mood group, participants recalled a specific time in their lives when they were very happy and then wrote about it (see KrauthGruber \& Ric, 2000, for a similar mood-induction procedure). Participants were told to focus on specific details of the incident and to describe why they were happy. When they finished writing about one incident, they were

\footnotetext{
${ }^{2}$ We could locate only a single study that has examined the effect of ruminative activity on aggressive behavior. Konecni (1974) found that preventing people from engaging in rumination reduced direct aggression toward an insulting confederate. No studies, however, have examined the relation between rumination and displaced or triggered displaced aggression.
} 
told to write about another and to continue this process for $25 \mathrm{~min}$. The positive mood condition served as an additional control.

The experimenter informed participants that the third part of the study investigated the impact of audio and visual stimuli on problem solving. Participants watched a video of an undergraduate research assistant who stated trivia questions aloud and displayed a card with the multiple-choice foils for each question. Participants answered as many questions as they could. They were told that the research assistant on the tape had applied for a coveted position as a paid researcher in a faculty member's lab and that the faculty member wanted participants to evaluate applicants. At the conclusion of the tape, the experimenter reentered the room, retrieved each participant's trivia answer sheet, provided a summary sheet indicating the average score obtained by a group of engineering students on the same trivia game from the previous semester, and then left to "score" the test.

Within each of the three groups (i.e., rumination, distraction, and positive mood), participants were randomly assigned to the trigger or the no-trigger group. In the trigger group, the research assistant read the trivia questions too quickly, mispronounced some of the words and names (e.g., Leonardo da Vinci was pronounced Leon Divinsky), and occasionally mixed up the multiple-choice responses (e.g., presenting the multiplechoice responses to Question 12 after reading Question 9). In addition, participants were told that they did poorly in comparison with the average engineering student, but they were not insulted about their performance. In the no-trigger group, the research assistant read the trivia questions slowly, made no pronunciation errors, and correctly matched the questions with the appropriate sets of multiple-choice answers. In addition, participants were told that their score was about the same as that of the engineering students' average score. Pedersen et al. (2000, Study 1) have successfully used this trigger manipulation in previous research.

After obtaining feedback from the experimenter about their performance on the trivia game, participants received a four-page packet containing dependent measures and manipulation check items. The aggression measure, positioned on the first page, consisted of five items that were rated on an 11-point scale ranging from 1 (strongly agree) to 11 (very strongly disagree). One item assessed how strongly they recommended the research assistant for the paid assistantship position. Four other items assessed their evaluation of the confederate on the following dimensions: likable, friendly, competent, and intelligent. Aggression is generally defined as any behavior intended to harm another person (Bushman \& Anderson, 2001). By giving a negative evaluation, participants could harm the research assistant's chance to obtain a highly coveted paid job.

The second page of the packet contained the trigger manipulation check items. Participants gave their general impression of the research assistant's performance on the trivia game. Three items assessed the participants' emotional reaction to the assistant's performance (viz., irritated, happy, and angered or upset), whereas the remaining four items assessed how well the research assistant performed the task (viz., read the questions slowly, spoke clearly, administered the questions efficiently, and read the questions correctly). Again, all items were rated on an 11-point scale ranging from 1 (strongly agree) to 11 (very strongly disagree).

The third page of the packet contained the rumination manipulation check items. Two items assessed a cognitive response to the rumination manipulation. Participants rated how often and how strongly they thought about their performance on the anagram task (viz., the initial provocation) while performing the imagination and creativity task (viz., the 25-min assignment that served as the manipulation of rumination). These two items were rated on a 7-point scale ranging from 1 (not at all) to 7 (very often or very strongly). The other six items assessed affective responses to the rumination manipulation (i.e., angry, grouchy, happy, irritated, pleased, and $s a d$ ). They were rated on an 11-point scale ranging from 1 (strongly agree) to 11 (very strongly disagree).

The fourth page of the packet contained a modified Mood Adjective Check List (Nowlis, 1965) to report how the participants were affected by the initial provocation. On an a priori basis, 10 adjectives were used to measure provocation-induced negative affect (i.e., angry, defiant, hostile, disgusted, irritable, scornful, annoyed, loathing, grouchy, and frustrated). Participants were instructed to describe how they felt after performing the anagram task (viz., the provocation). The items were scored on a 4-point scale ranging from 0 (definitely did not feel this way) to 3 (definitely did feel this way). Responses from the 10 items were summed to form a composite score (Cronbach's $\alpha=.90$ ). Finally, participants were fully debriefed.

\section{Results}

\section{Preliminary Analyses}

Sex differences. There were no main effects or interactions involving sex for any of the measures. Thus, the data for men and women were combined for subsequent analyses.

Statistical assumptions. Tukey's (1977) box plot was used to identify extreme outliers, but none were found.

Trigger manipulation checks. To assess the effectiveness of the trigger manipulation, participants rated their emotional response to the research assistant's performance (viz., irritated, angered or upset, or happy). They also rated the research assistant's performance on the following dimensions: (a) read the questions slowly, (b) spoke clearly, (c) administered the questions efficiently, and (d) read the questions correctly. After the happy and task performance items were reverse scored, the seven items were averaged to form a composite score (Cronbach's $\alpha=.93$ ). As expected, composite scores were significantly higher in the trigger group $(M=7.08, S D=1.72)$ than in the no-trigger group $(M=3.02, S D=1.38), t(40)=8.45, p<.01, d=2.60$.

A further analysis using this same composite variable assessed whether the manipulation of rumination differentially affected participants' reactions to a subsequent triggering event. Among triggered participants, those in the rumination condition reported a more negative reaction to the triggering event than did those in both the distraction and positive mood conditions, $t(19)=2.52$, $p<.05$.

Rumination manipulation checks. To assess the effectiveness of the rumination manipulation, participants indicated how often and how strongly they thought about the anagram task while completing the imagination and creativity task. Because of their high internal consistency (Cronbach's $\alpha=.87$ ), the two items were averaged to form a composite score. Analysis of variance (ANOVA) revealed that the three groups (i.e., rumination, distraction, and positive mood) did not differ on this purely cognitive measure of rumination, $F(2,38)=0.15, p>.05$.

Participants indicated their affective response to the rumination manipulation (viz., how angry, grouchy, happy, irritated, pleased, and sad they felt). After the positive adjectives were reverse scored, the six items were averaged to form a composite negative affect score (Cronbach's $\alpha=.88$ ). ANOVA showed a main effect for group, $F(2,30)=4.64, p<.05$. To interpret the main effect, two orthogonal contrasts were performed. The first contrast showed that participants in the rumination group experienced more negative affect while completing the imagination and creativity task than did those in the distraction and positive mood groups $(M=5.86, S D=1.90$, and $M=3.78, S D=1.84), F(1,30)=$ 9.23, $p<.01, d=1.18$. The second contrast showed that the 
distraction and positive mood groups did not differ $(M=3.88$, $S D=1.87$, and $M=3.68, S D=1.80), F(1,30)=0.06, p>.05$.

\section{Primary Analyses}

Aggression. Evaluations of the research assistant measured displaced aggression (i.e., recommendation of the research assistant for the paid assistantship position and the evaluative ratings of liking, friendliness, competence, and intelligence). A negative evaluation would harm the research assistant's likelihood of obtaining a highly coveted paid assistantship. Scores on the five items were summed (Cronbach's $\alpha=.86$ ) and analyzed using a 3 (rumination, distraction, positive mood) $\times 2$ (trigger, no trigger) between-subjects ANOVA.

The analysis revealed a main effect for trigger, $F(1,36)=8.79$, $p<.01$. This main effect, however, was qualified by a Trigger $\times$ Rumination interaction, $F(1,36)=3.53, p<.05$ (see Figure 1 ). Rumination influenced aggression in the presence of a triggering event but did not influence aggression in the absence of a triggering event, $F(2,36)=3.25, p<.05$, and $F(2,36)=0.96, p>.05$, respectively. In the presence of a triggering event, participants in the rumination group were more aggressive than were those in both the distraction and positive mood groups, $F(1,36)=6.11$, $p<.05, d=0.92$. The distraction and positive mood groups did not differ, $F(1,36)=0.39, p>.05$.

Provocation-induced negative affect and aggression. Given the long temporal gap between the initial provocation and the measurement of aggression, we expected to find a link between provocation-induced negative affect (assessed by the Mood Adjective Check List final postmeasure items) and aggression only among participants induced to ruminate during that time interval. We did not expect evidence of such a link among participants in the distraction and positive mood groups.

As we expected, provocation-induced negative affect was associated with aggression among those in the rumination group $(r=$ $.56, p<.05)^{3}$ but not among those in the distraction and positive

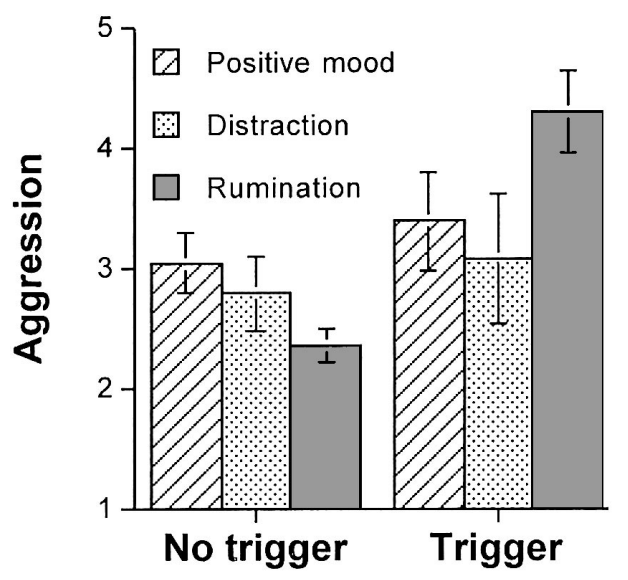

Figure 1. Interactive effects of rumination and a triggering event on aggression (Study 1). Aggression was measured using the evaluation that participants gave an individual for a coveted research assistantship position. Scores could range from 1 to 11 , with higher scores indicating a more negative evaluation. Vertical bars denote plus or minus one standard error. mood groups ( $r \mathrm{~s}=-.27$ and -.35 , respectively, $p \mathrm{~s}>.20$ ). The correlation for the rumination group reliably differed from the correlations for the distraction and positive mood groups $(z \mathrm{~s}=$ 2.03 and 2.26, $p \mathrm{~s}<.05$ ). The correlations for the distraction and positive mood groups did not differ $(z=0.23, p>.80)$. Thus, not only did rumination augment participants' negative affect (see the rumination manipulation check results), but among those induced to ruminate, the magnitude of their negative affective reaction to the provocation was in turn associated with greater aggressive response to the trigger. Moreover, within the rumination condition, other correlations reflecting intermediate steps in a causal chain that links provocation-induced negative affect to aggressive responding to the trigger were also significant. Provocation-induced negative affect correlated with negative reactions to the trigger as assessed by the trigger manipulation check $(r=.64, p<.05)$, and, in turn, these negative reactions to the trigger were associated with a stronger aggressive response to it $(r=.70, p<.01)$.

\section{Discussion}

In Study 1, we examined whether ruminating about a provoking event increased the displaced aggression elicited by a minor triggering event. As expected, participants induced to ruminate after being provoked were more aggressive after a minor triggering event than were those who were distracted or induced to think positively. In the absence of a triggering event, rumination did not intensify displaced aggression.

Consistent with Berkowitz's $(1989,1990,1993)$ model of aggression, provocation-induced negative affect was associated with increased displaced aggression for participants induced to ruminate but not for those who were distracted or were induced to think positively. Other correlational evidence suggested that within the rumination condition, the stronger the provocation-induced negative affect, the more negative was participants' reaction to the trigger. And the more negative the reaction to the trigger, the more aggression it elicited. These data are consistent with a model in which (a) rumination that follows a provocation augments negative affect; (b) cognitive representations of that negative affect in turn prime reactivity to a trigger, thereby augmenting negative reactions to it; and (c) these negative reactions to the trigger in turn augment aggressive retaliation. By contrast, in the nonrumination conditions, the minor triggering event was experienced as only mildly aversive and was not strong enough to elicit an aggressive response.

\section{Study 2}

One limitation of Study 1 is that we did not include noprovocation conditions. Previous research has shown that a minor trigger does not increase aggression in the absence of provocation (Pedersen et al., 2000). Therefore, in Study 1, we assumed that rumination would not increase triggered displaced aggression in the absence of provocation. However, such a conclusion cannot be drawn unless provocation is manipulated in the experimental de-

\footnotetext{
${ }^{3}$ To reduce the impact of outliers, we calculated this association by using percentage bend correlations instead of Pearson correlations (Wilcox, 1996).
} 
sign. In Study 2, therefore, we included no-provocation conditions. Additionally, to provide a conceptual replication of Study 1, we used different operational definitions of the key variables in Study 2.

Study 2 also further investigated the process by which rumination increases displaced aggression (Miller et al., 2003). Correlational evidence from Study 1 suggested that rumination not only maintains negative affect over time but also increases the chances that the triggering event will be experienced more negatively and thereby will increase displaced aggression. Study 2 more explicitly tested this mediational model. Specifically, we expected that provoked participants who were induced to ruminate about a provocation would experience the triggering event more negatively than would those who did not ruminate. In turn, we expected these negative reactions to the trigger to mediate displaced aggression. We expected no such mediation for those not provoked.

\section{Method}

\section{Participants and Design}

Participants were 385 undergraduates at Iowa State University (194 women and $191 \mathrm{men}$ ) who received extra course credit for voluntarily taking part in a 2 (rumination, distraction) $\times 2$ (provocation, no provocation) $\times 2$ (trigger, no trigger) between-subjects design.

\section{Procedure}

Participants arrived at the lab under the ruse that they were taking part in an impression formation study with a same-sex partner. They were told they would engage in several tasks that would help them form an impression of their partner. As a rationale for the displaced-aggression measure, participants were told that one task involved tasting food, which would give them an idea of the types of food their partner liked. They were given a "food preference form" and told that they and their partner would each taste and rate one of the foods on the list. Participants then rated how much they liked certain types of food (e.g., dairy food, snack food, seafood, spicy food). Ratings (e.g., I like spicy food) were made on a 21-point scale ranging from -10 (strongly disagree) to 10 (strongly agree).

The second task ostensibly assessed verbal skills. All participants saw a series of scrambled letters on a computer screen for $5 \mathrm{~s}$. Participants were given $7 \mathrm{~s}$ to solve the anagram by writing the correct solution on an answer sheet and by saying the answer aloud over an intercom. Finally, they were given $5 \mathrm{~s}$ to speak into the intercom a first-person sentence that used the word. The experimenter emphasized that participants must loudly and clearly state their solution and sentence.

The actual purpose of the anagram task was to provoke or not provoke participants. Those in the provocation condition were subjected to three aggravations. First, they listened to loud and distracting background music (viz., Holst's Mars, the Bringer of War) while working on the anagrams. Second, the anagrams were difficult (e.g., DMMPAIUNNEO unscrambled to spell PANDEMONIUM). Third, the experimenter interrupted and rudely insulted them three times during the anagram task. After the 4th anagram, the experimenter said, via the intercom, "Look, I can barely hear you. I need you to speak louder please." After the 8th anagram, the experimenter said in a louder and angrier tone, "Hey, I still need you to speak louder please!" After the 12th anagram, the experimenter said in a loud, frustrated, and exasperated tone, "Look, this is the third time I've had to say this! Can't you follow directions? Speak louder!" The experimenter's insults were prerecorded and played over an intercom system. This provocation procedure has been successfully used in previous research (e.g., Pedersen et al., 2000).
Participants in the no-provocation condition had a more pleasant experience during the anagram task. First, although they also listened to background music, it was softer and less distracting (viz., Handel's Water Music). Second, they were given simpler anagrams to solve (e.g., ESTT for TEST). Third, the experimenter did not insult them. After the participants completed the 4th, 8 th, and 12th anagrams, the experimenter simply said, "You have just completed the 4th [8th or 12th] anagram," respectively.

After participants completed the anagrams, the experimenter took their solutions to their partner, ostensibly for evaluation. Participants were told that the next activity involved writing an essay. Participants in the rumination condition were told that another professor, unrelated to the study, was interested in learning about participants' perceptions of the research process. The other professor was asking students to write an essay about their experiences as a research participant. Participants were instructed to write about what they had done from the start of the study until the present time as well as the thoughts and feelings they had experienced. They were also told to write about any individuals whom they encountered in the study and their thoughts and feelings toward those individuals. Note that the only individual with whom participants had interacted was the experimenter. Participants were told to spend $20 \mathrm{~min}$ writing their essay.

Participants in the distraction condition were also asked to write an essay for another professor conducting research unrelated to the current study. The other professor was supposedly studying visual maps and asked students to write essays about the layout of the college campus. Participants were instructed to create a mental map of the campus and describe what they saw. They were to write about the various buildings, the purpose of the various buildings, the landscape architecture of the campus, and the spatial relations (e.g., location of buildings) on campus. Distracted participants were also told to spend 20 min writing their essay.

After the participants completed their essay, the experimenter returned with the anagram solution sheet supposedly completed by each participant's partner. The experimenter instructed participants to examine the solutions and evaluate their partner's performance. The ostensible partner had solved the same list of anagrams that the participant had solved, plus three more. If the participant had fewer than three incorrect solutions, then the partner correctly solved all of the anagrams, which happened $7 \%$ of the time. The evaluation form asked participants to rate their partner's anagram performance by using the following items: (a) "Taking into account the difficulty level of the task, the other participant's overall performance on the anagram test seems ____; (b) "If you had to guess, the concentration level used by the other participant on the anagram task appears to be "; and (c) "Based on the limited information I have, it seems that the likelihood of the other participant performing very well in a class at Iowa State University that requires good verbal skills is __." Ratings were made on a 21-point scale ranging from -10 (very poor) to 10 (very good). There was also space for written comments.

After the participants had evaluated their partner, the experimenter returned with the partner's evaluation of the participant's anagram performance. Participants in the trigger condition received scores of -2 for overall performance, -1 for concentration level, and -1 for success in a class requiring good verbal skills, along with the following written comment: "Although the task was difficult, I would have thought a college [class standing of the participant; e.g., sophomore] would have performed better." Participants in the no-trigger condition received ratings of 2 for overall performance, 1 for concentration level, and 1 for success in a class requiring good verbal skills, along with the following written comment: "Although the task was difficult, I thought my partner did a fairly good job for a college [class standing of the participant]." Thus, the trigger evaluations were slightly negative, whereas the no-trigger evaluations were slightly positive. This trigger procedure has been successfully used in previous research (e.g., Pedersen et al., 2000, Study 2).

The next phase of the study served as the displaced-aggression opportunity (Lieberman, Solomon, Greenberg, \& McGregor, 1999). After the 
participants finished reading the evaluation, the experimenter returned with the partner's "food preference form." Participants were told to examine it and note what types of food their partner did and did not like to eat. They also were told that they would next sample one of the items on the list. For all participants, their partner positively rated most of the foods. However, the partner rated spicy foods as -9 on a scale ranging from -10 to 10 . The partner also provided the written comment "I like most of the foods listed above, but I hate spicy foods."

The experimenter then returned with a box containing a 3.5-oz (99.22-g) Dixie cup, a container of hot sauce, a lid, two spoons, and a cup of water. The hot sauce was a mixture of $5 \mathrm{oz}(141.75 \mathrm{~g})$ of Melinda's original habanero pepper sauce XXX HOT combined with $12 \mathrm{oz}(340.19 \mathrm{~g})$ of Heinz chili sauce. Participants were told that they were randomly assigned to eat pretzels and that their partner was randomly assigned to eat hot sauce. Participants were also told that their partner would decide how many pretzels they would consume and that they would decide how much hot sauce their partner would consume. It was emphasized that they, and their partner, would be required to consume the entire amount of food product that they were given. Participants then sampled the hot sauce, which was very spicy. They were given water to drink if it was too spicy. The experimenter then instructed them to spoon into the cup as much hot sauce as they wanted their partner to consume. Participants were also told to place a lid on the cup so the experimenter did not know how much hot sauce the participants put in the cup. After the participants finished allocating the hot sauce, the experimenter removed their cup and returned shortly with a cup containing three pretzels for the participants to eat. The participants then rated how much they liked eating the pretzels.

Participants also rated how they felt about their partner's evaluation of their own anagram performance (i.e., the triggering event). We expected these ratings to mediate the effect of the trigger on displaced aggression for participants who ruminated about the provocation. Participants rated how angry it made them feel, how much it bothered them, whether it was overly critical, whether it was harsh, and whether it was nasty. Ratings were made on a 10-point scale ranging from 1 (strongly disagree) to 10 (strongly agree). Other items were added as fillers. These key items were standardized and summed to yield an overall composite score of how negatively participants perceived the evaluation (Cronbach's $\alpha=.88$ ). Higher scores indicated a more negative reaction to the anagram evaluation. To control for order effects, half of the participants rated their anagram evaluation before allocating hot sauce to their partner, whereas the other half allocated hot sauce to their partner before rating their anagram evaluation. Finally, the experimenter probed participants for suspicion and debriefed them.

\section{Results}

\section{Preliminary Analyses}

Statistical assumptions. Tukey's (1977) box plot was used to identify potential outliers in the primary dependent variable- the amount of hot sauce allocated to the ostensible partner. Because extreme outliers can unduly influence least squares estimates, they were removed from the data set (Barnett \& Lewis, 1978). An extreme outlier was defined as allocating more than $25 \mathrm{~g}$ of hot sauce to the partner. Removing the extreme outliers left a total sample size of 347 participants (186 men and 161 women). A Fisher's exact test showed that the outliers removed did not depend on experimental condition $(p>.05)$.

Order effects. The order in which participants completed the measures did not influence their level of aggression, either alone or interacting with other variables $(p s>.05)$. Thus, the data from the two orders were combined for subsequent analyses.

\section{Primary Analyses}

We used a 2 (provocation, no provocation) $\times 2$ (rumination, distraction) $\times 2$ (trigger, no trigger) $\times 2$ (participant sex) betweensubjects factorial design to analyze the data. We obtained significant main effects for provocation and trigger and a two-way Rumination $\times$ Trigger interaction, $F \mathrm{~s}(1,331)=8.12,8.67$, and 4.01 , respectively, $p$ s $<.05$. However, these lower order effects were qualified by the predicted three-way Provocation $\times$ Rumination $\times$ Trigger interaction, $F(1,331)=4.12, p<.05$. To interpret the three-way interaction, the two-way interactions between rumination and triggering event were examined separately for provoked and nonprovoked participants. For provoked participants, the Rumination $\times$ Trigger interaction was significant, $F(1$, $161)=7.46, p<.01$. As shown in Figure 2, in the presence of a minor triggering event, participants allocated more hot sauce if they had been induced to ruminate than if they were distracted, $t(75)=3.21, p<.01, d=0.68$. In the absence of a triggering event, there was no difference in hot sauce allocation between participants induced to ruminate and participants who were distracted, $t(86)=0.56, p>.05, d=0.13$.

For nonprovoked participants, the Rumination $\times$ Trigger interaction was not significant, $F(1,178)=0.07, p>.05$. As shown in Figure 3, participants induced to ruminate and participants who were distracted did not differ in how much hot sauce they allocated to their partner, regardless of whether there was or was not a minor triggering event, $t(83)=0.20, p>.05, d=0.04$, and $t(95)=0.59$, $p>.05, d=0.14$, respectively.

Other effects less central to the hypotheses being tested were also found. Overall, men were more aggressive than women, $F(1$, $331)=5.09, p<.05, d=0.80$. There was also a significant Rumination $\times$ Sex interaction, $F(1,331)=5.85, p<.05$. In the rumination condition, there were no sex differences in aggression, $t(176)=-0.11, p>.05, d=-0.03$. In the distraction condition, men were more aggressive than women, $t(167)=3.35, p<.01$, $d=0.52$. Participants' sex did not interact with trigger or provocation $(p \mathrm{~s}>.05)$.

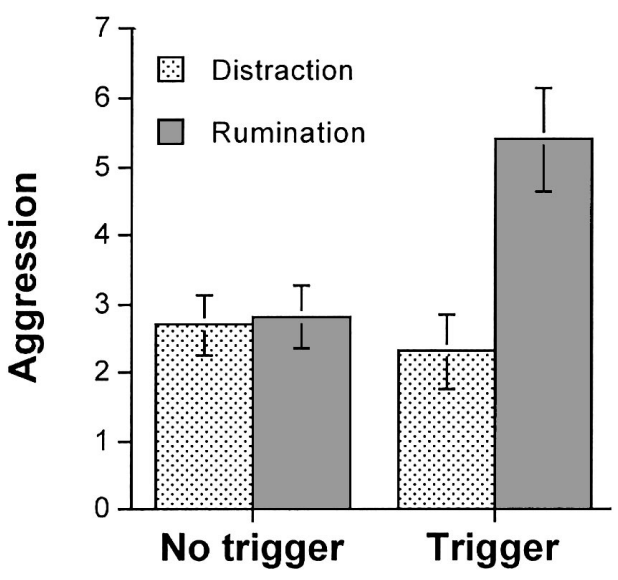

Figure 2. Effects of triggering event and rumination on aggression after an initial provocation (Study 2). Aggression was measured using the number of grams of hot sauce that participants gave a confederate (who hated spicy food) to consume. Vertical bars denote plus or minus one standard error 


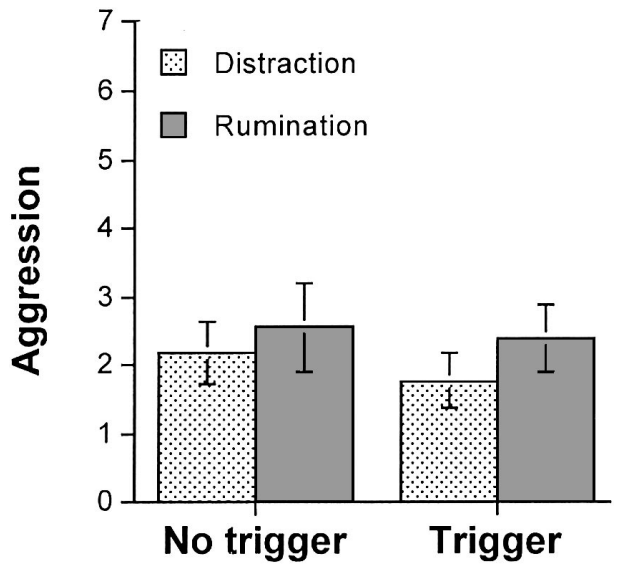

Figure 3. Effects of triggering event and rumination on aggression without an initial provocation (Study 2). Aggression was measured using the number of grams of hot sauce that participants gave a confederate (who hated spicy food) to consume. Vertical bars denote plus or minus one standard error.

\section{Mediation Analyses}

Negative reactions to the triggering event were hypothesized to mediate the relationship between the triggering event and displaced aggression among provoked participants who had been induced to ruminate about the provocation (i.e., the provocationrumination condition). For the other three conditions (provocation-distraction, no provocation-rumination, and no provocation-distraction), no mediation was hypothesized. Mediation analyses were conducted to test these hypotheses by using the LISREL 8.52 computer program (Jöreskog \& Sörbom, 2002). Table 1 presents the variance-covariance matrices used for analyses.

For participants in the provocation-rumination condition, a causal path was specified linking trigger $(1=$ trigger, $0=$ no trigger) to negative reactions to the trigger. A second path was specified linking these negative reactions to displaced aggression. For participants in the other three conditions, a causal path was specified linking negative trigger reactions to aggression. However, the path between negative reactions to the trigger and aggression was set to 0 . We hypothesized that, regardless of condition, a mildly negative trigger would be interpreted more negatively than a neutral evaluation in all conditions. The proposed model exhibited a good fit to the data, $\chi^{2}(7, N=337)=7.19, p>$ .05 ; goodness-of-fit index $=.97$; comparative fix index $=1.00$, root-mean-square error $=0.14$. For participants in the provocation-rumination condition, the path between trigger and negative reactions to it was positive and significant $(\beta=.46, z=$ 5.48, $p<.05)$. Also, the path between negative reactions to the trigger and aggression was positive and significant $(\beta=.37, z=$ $3.44, p<.05)$. These results suggest that for provoked participants who were induced to ruminate about the provocation, a minor triggering event produced a negative reaction to the trigger, which in turn increased displaced aggression (see Figure 4).

For the other conditions, the causal paths between trigger and negative reactions to the trigger were positive and significant. To examine the effect of constraining the causal paths between negative reactions to the trigger and aggression to 0 for the other conditions, another model was run in which these paths were allowed to vary. Allowing the paths to vary did not significantly improve the fit of the model over the hypothesized model, $\chi^{2}(3$, $N=337)=2.87, p>.05$. Moreover, the causal paths between negative reactions to the trigger and displaced aggression were not significant $(p s>.05)$. This suggests that negative reactions to the trigger and aggression were not related to each other in the other conditions.

The mediation analyses provide support for the hypothesized model. However, for provoked participants who ruminated, it is possible that the triggering event had a direct effect on displaced aggression. Consequently, we modified the hypothesized model by adding a direct causal path between the trigger and displaced aggression and treating that path as a free parameter. Inclusion of this path, however, did not significantly improve the fit of the model, $\chi^{2}(3, N=77)=3.41, p>05$. Moreover, the direct path between trigger and displaced aggression was not significant $(z=$ $1.87, p<.05)$.

The mediation observed among participants in the provocationrumination condition can be explored by examining the indirect effects estimate. The indirect effects estimate and its significance test are based on Sobel's (1982) method, which divides the indirect effects estimate by the standard error and compares that value with a standard normal distribution. Because this significance test has low statistical power, a modified $z^{\prime}$ distribution was used rather than a standard normal distribution (MacKinnon, Lockwood, Hoffman, West, \& Sheets, 2002). For the hypothesized model, the

Table 1

Variance-Covariance Matrices Used for LISREL Mediation Analyses in Study 2

\begin{tabular}{lrrr}
\hline Measure & 1 & 2 & 3 \\
\hline & Provocation-rumination group $(n=77)$ & \\
1. Trigger & 0.25 & & \\
2. Evaluation & 1.28 & 23.01 & 18.36 \\
3. Aggression & 0.78 & 7.53 & \\
\hline & Provocation-distraction group $(n=83)$ & \\
& & & \\
1. Trigger & 0.25 & 14.67 & \\
2. Evaluation & 0.83 & 1.42 & \\
3. Aggression & 0.15 & & \\
\hline
\end{tabular}

No provocation-rumination group $(n=87)$

\begin{tabular}{lrrr} 
1. Trigger & 0.25 & & \\
2. Evaluation & 0.59 & 14.60 & \\
3. Aggression & 0.17 & 1.49 & 9.36 \\
\hline
\end{tabular}

No provocation-distraction group $(n=90)$

$\begin{array}{llr}\text { 1. Trigger } & 0.25 & \\ \text { 2. Evaluation } & 1.06 & 15.44 \\ \text { 3. Aggression } & 0.09 & 0.41\end{array}$
13.77

Note. Variances are on the diagonal, and covariances are below the diagonal. 


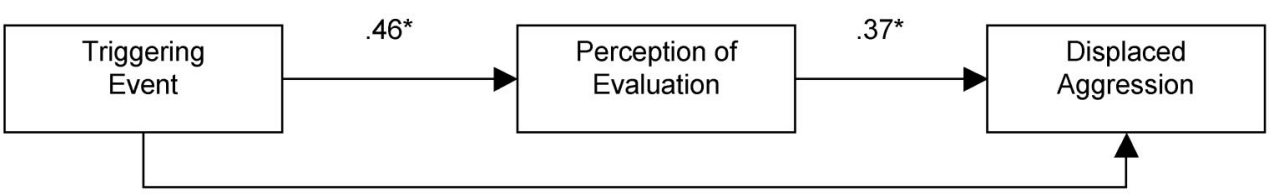

$\left(.36^{\star}\right) .19$

Figure 4. Negative reactions to the trigger as a mediator between trigger and displaced aggression for provoked participants who ruminated (Study 2). $* p<.05$.

indirect effect of trigger on displaced aggression via negative evaluation was significant $\left(\beta=.20, z^{\prime}=2.91, p<.05\right)$. Moreover, this remained true even after the direct path between trigger and displaced aggression was added to the model $\left(\beta=.17, z^{\prime}=\right.$ 2.97, $p<.05$ ).

Finally, we also examined a model that reversed the causal sequencing and thereby tested instead whether the aggression elicited by the trigger mediated participants' negative reaction to the triggering event. Analyses revealed that this reversed mediation model was not viable. In the full reversed causal model for the provocation-rumination group, the path between trigger and aggression was not significant. Moreover, dropping the direct path between trigger and negative reactions to the trigger reduced the fit of the model, $\chi^{2}(3, N=77)=41.59, p<.05$, goodness-of-fit index $=.88$. Thus, the data are not consistent with a model that sees the rumination-induced aggressive responding to the trigger as causing negative reactions to the trigger. In sum, the mediation analyses suggest that for provoked participants who ruminated about the provocation, their negative reaction to the triggering event mediated its effect on displaced aggression.

\section{Discussion}

Study 2 conceptually replicated the findings of Study 1 . Provoked participants who were induced to ruminate engaged in more triggered displaced aggression than did provoked participants who did not ruminate. The absence of either an initial provocation or a triggering event nullified the effect of rumination on displaced aggression. These results suggest that the triggering event, in itself, is indeed minor and not severe enough to elicit an aggressive retaliation.

On the basis of the theoretical model proposed by Miller et al. (2003), we hypothesized that ruminating about a provocation maintains an internal state that primes individuals to interpret triggering events more negatively than warranted and more deserving of an aggressive retaliation. In Study 2, we included a measure assessing negative reactions to the triggering event, and we found support for our hypothesis. Among provoked participants who ruminated, their negative reaction to the triggering event mediated the relationship between the triggering event and displaced aggression. Participants experienced the minor triggering event negatively (e.g., anger provoking, harsh, and overly critical), and this negative interpretation, in turn, prompted an aggressive retaliation.

The fact that people who ruminated about the provocation interpreted the trigger more negatively is related to research on the hostile attribution bias, in which one tends to perceive ambiguous actions by others as hostile (e.g., Crick \& Dodge, 1994). Numerous studies have shown a strong relationship between hostile attribution of intent and aggressive behavior among both children and adults (de Castro, Veerman, Koops, Bosch, \& Monshouwer, 2002; Epps \& Kendall, 1995). Thus, it appears that ruminating about a provocation increases the likelihood that people will perceive minor triggering events in a hostile manner.

One might hypothesize that it was the triggering event itself, not rumination, that prompted displaced aggression. Evidence, however, refutes this alternative explanation. First, under conditions of no provocation, the presence or absence of a triggering event had no effect on displaced aggression. This suggests that under normal circumstances the triggering event in itself is insufficient to prompt an aggressive retaliation. In addition, the triggering event had no effect on displaced aggression either among those nonprovoked or among those both provoked and distracted. Although nonprovoked and provoked-distracted participants interpreted a minor triggering event negatively, that interpretation was not sufficient enough to prompt aggression.

Finally, Miller et al. (2003) suggested that the contribution of rumination to displaced aggression becomes important when a lengthy delay separates the initial provocation and the subsequent triggering event. In Studies 1 and 2, through the use of a 20-25min delay period, the interval between provocation and trigger exceeded the 10-15-min duration over which provocation-induced arousal typically persists (Fridhandler \& Averill, 1982; Tyson, 1998). Moreover, this delay substantially exceeded that used in all prior studies of triggered displaced aggression. Yet, it is still conceivable that some arousal generated by the initial provocation lingered and this arousal, not rumination, prompted displaced aggression. If, however, the delay between provocation and trigger is lengthened substantially beyond a 25-min interval, then it seems much more likely that ensuing displaced aggression is ruminatively based rather than arousal-based (Miller et al., 2003). Therefore, in Study 3, we extended the delay between provocation and the triggering event to $8 \mathrm{hr}$.

\section{Study 3}

The goal of Study 3 was to replicate the findings of Studies 1 and 2 by using a considerably longer rumination period ( $8 \mathrm{hr}$ as opposed to 20 or $25 \mathrm{~min}$ ) and using different operational definitions of the key variables. In the presence of a triggering event, we expected higher levels of displaced aggression among participants who had been induced to ruminate about the provocation than among those who had not been induced to ruminate about the provocation. In the absence of a triggering event, we expected low 
levels of displaced aggression regardless of whether participants were induced to ruminate about the provocation. Finally, because we showed in Study 2 that in the absence of an initial provocation an induction of rumination had no aggression-augmenting effect (irrespective of the presence or absence of a trigger), we omitted no-provocation conditions in Study 3.

\section{Method}

\section{Participants and Design}

Participants were 93 undergraduate students from Iowa State University (59 women and 34 men) who served in a 2 (rumination, no rumination) $\times$ 2 (trigger, no trigger) between-subjects design. Students received extra course credit in exchange for their voluntary participation.

\section{Procedure}

Participants were tested individually, but each was led to believe that he or she would be interacting with two other participants of the same sex-one in the morning and another in the evening. Participants were told that the study involved writing essays on controversial topics, solving anagrams, and competing on a reaction time task. All of the tasks were presented as ways to obtain information that could be used to form an impression of the "other participants" in the study, which was the ostensible purpose of the study.

First, each participant wrote a one-paragraph essay on abortion, either prochoice or prolife (whichever the participant supported). Then, the participant's essay was taken and ostensibly shown to the other (nonexistent) participant for evaluation. Meanwhile, the participant evaluated the other participant's essay, which always disagreed with the attitudinal position advocated by the participant (e.g., participants who wrote prochoice essays evaluated pro-life essays). To augment credibility, male and female handwritten versions of the standard essays were matched to the sex of each participant. A short time later, the experimenter brought back the participant's own essay along with comments ostensibly made by the other participant. All participants received bad evaluations consisting of negative ratings on organization, originality, writing style, clarity of expression, persuasiveness of arguments, and overall quality. Individual scale ratings on these dimensions varied from -10 to -8 on a 21 -point scale ranging from -10 (very poor) to 10 (very good). An added handwritten comment stated, "This is one of the worst essays I have read!" This provocation procedure has been used successfully in previous research (Bushman, 2002; Bushman \& Baumeister, 1998; Bushman, Baumeister, \& Phillips, 2001; Bushman et al., 1999; Pedersen et al., 2000).

Participants were assigned randomly to either a rumination or a norumination group. In the rumination group, they were told that their evening partner would have access to their essay and essay evaluation. After leaving to photocopy these materials for the participants' evening partner, the experimenter returned a few minutes later and said, "Please take your essay and essay evaluation with you so you can think about them during the day. Also think about what you might write to justify your position and explain your essay evaluation to your partner tonight." In the no-rumination group, participants were told that their evening partner would not have access to their essay or essay evaluation. They were told to tear up both forms and throw them in the trash.

Exactly $8 \mathrm{hr}$ later, participants returned for the evening session. First, they completed an anagram task. To minimize frustration, participants solved the easy anagrams described in Study 2 (e.g., ESTT for TEST). Then, they evaluated their partner's anagram performance and were assigned to trigger or no-trigger conditions as implemented in the procedure of Study 2.
The next part of the procedure, presented as a competitive reaction time task, was based on a paradigm developed by Taylor (1967). Previous research has established the construct validity of Taylor's paradigm (e.g., Anderson \& Bushman, 1997; Bernstein, Richardson, \& Hammock, 1987; Giancola \& Zeichner, 1995). The ostensible purpose of the reaction time task was to give the participant an idea of what his or her partner was like in a competitive situation. Each participant was told that he or she and the partner would have to press a button as fast as possible in response to a visual cue and whoever was slower would receive a blast of noise through headphones. For each competitive reaction time trial, the participant was permitted to set in advance the intensity of the noise to be received if the other person lost the competition. It could vary between $60 \mathrm{~dB}$ (Level 1) and $105 \mathrm{~dB}$ (Level 10). A nonaggressive no-noise setting (Level 0) was also offered. In addition to deciding the intensity, the winner decided the duration of the loser's suffering, because the duration of the noise depended on how long the winner held down the button. In effect, the participant controlled a weapon that could be used to blast the other person with loud noise if the participant won the competition to react faster.

The reaction time task consisted of 25 trials. As a constant feature in all conditions, the preprogrammed intensity and duration of noise allegedly set by the other person were steadily increased across blocks of trials. After the initial trial, the remaining 24 trials were divided into three blocks with 8 trials in each block. The noise durations, allegedly set by the other participant, ranged from $0.25 \mathrm{~s}$ to $2.50 \mathrm{~s}$. The average noise intensity and duration set by the confederate were, respectively, 2.50 and $0.63 \mathrm{~s}$ on Block 1, 5.50 and $1.38 \mathrm{~s}$ on Block 2, and 8.50 and $2.47 \mathrm{~s}$ on Block 3. The participant heard noise on half of the trials within each block (randomly determined). An iMac computer controlled the events in the reaction time task and recorded the noise levels and durations set by the participant.

After the reaction time task, participants were given a thought-listing task (Cacioppo \& Petty, 1981; Miller \& Baron, 1973). They were given 3 min to list whatever they thought about between the morning and evening sessions. The thought-listing task was used to check the rumination manipulation. In comparison with participants in the no-rumination group, participants in the rumination group were expected to write more about the negative essay evaluation that they had received. Finally, participants were fully debriefed.

\section{Results}

\section{Preliminary Analyses}

Sex differences. There were no main effects or interactions involving sex for any of the measures. Therefore, we pooled the data from men and women for all subsequent analyses.

Statistical assumptions. As in Studies 1 and 2, Tukey's (1977) box plot was used to identify extreme outliers on the displacedaggression measure. Eight outliers were detected. Fisher's exact test revealed that the outliers did not differ across conditions ( $p>$ .05 ). This left a total of 85 participants (55 women and $30 \mathrm{men}$ ) for analyses.

Rumination manipulation check. Two independent raters, who were naive to the experimental conditions, counted (a) the number of words participants listed about the negative essay evaluation they had received, (b) the number of words that expressed anger directly against the person who had insulted their essay, and (c) the total number of words listed. Because the intraclass correlations between raters were high $(>.90)$, the counts for the two raters were averaged (Shrout \& Fleiss, 1979).

We calculated the proportion of the total number of words listed that focused on the negative essay evaluation and the proportion of angry words. As expected, participants in the rumination group 
thought more about the negative essay evaluation they had received than did those in the no-rumination group $(M=0.69, S D=$ 0.34 , and $M=0.41, S D=0.37$, respectively), $t(83)=3.68, p<$ $.01, d=0.81$. More than two thirds of the thoughts listed by people in the rumination group focused on the negative essay evaluation they had received, whereas fewer than half of the thoughts listed by people in the no-rumination group focused on the negative essay evaluation they had received. Similarly, participants in the rumination condition expressed more anger toward the person who insulted them than did those in the no-rumination group $(M=0.40, S D=0.40$, and $M=0.23, S D=0.32$, respectively), $t(83)=2.17, p<.04, d=0.48$. People who ruminated expressed almost twice as many angry words about the person who insulted them. Thus, it appears that the rumination manipulation was effective. For example, a participant in the rumination group wrote that she thought the evaluation was a "joke" and that her partner was "overly critical" and not "openminded." In contrast, a participant in the no-rumination group wrote that he thought about such things as "Christmas ... e-mail ... my mom" while making no mention of the essay.

\section{Primary Analyses}

The intensity and duration of noise that participants set for their evening partner were positively correlated $(r=.47, p<.0001)$. The pattern of results obtained for the two aggression measures also was similar. Consequently, following the procedure of previous research (e.g., Bushman, 2002; Bushman \& Baumeister, 1998; Bushman et al., 1999, 2001), noise intensity and noise duration were standardized and summed to obtain a more reliable measure of aggression.

We were interested only in the intensity and duration of noise that participants set for the "other participant" on the first trial of the competitive reaction time task. After the first trial, aggression converged on what people believed the other person had done (i.e., tit-for-tat responding). This is consistent with many other findings that confirm the importance of reciprocation norms in determining levels of aggressive behavior (e.g., Bushman, 2002; Bushman \& Baumeister, 1998; Bushman et al., 1999, 2001).

As expected, we obtained a significant Rumination $\times$ Trigger interaction for aggression on the first trial of the competitive reaction time task, $F(1,81)=4.30, p<.05, M S E=0.97$ (see Figure 5). In the presence of a triggering event, those induced to ruminate about the negative evaluation of their essay were significantly more aggressive than those not induced to ruminate, $t(81)=2.17, p<.04, d=0.48$. In the absence of a triggering event, rumination did not influence aggression, $t(81)=0.72, p>$ $.05, d=0.16$. After the first trial, the noise levels set by the participant matched those set by the "partner" regardless of experimental condition.

\section{Discussion}

The key findings in Study 3 conceptually replicated those from Studies 1 and 2 but in the context of a much longer rumination period ( $8 \mathrm{hr}$ vs. 20 or $25 \mathrm{~min}$ ). Participants induced to ruminate about the provocation (by telling them that their evening partner would have access to their essay and evaluation) exhibited more

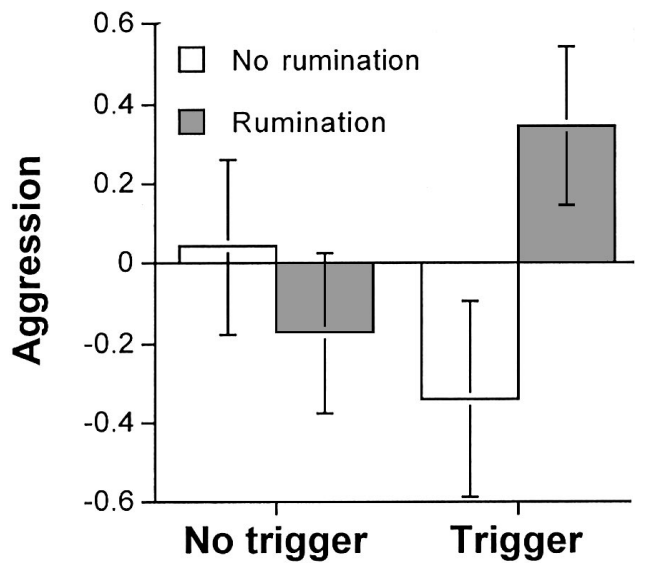

Figure 5. Interactive effects of rumination and a triggering event on aggression (Study 3). Aggression is the sum of standardized scores for noise intensity and noise duration. Vertical bars denote plus or minus one standard error

triggered displaced aggression than did those who were not induced to ruminate about the provocation. Miller et al. (2003) argued that arousal-based explanations of displaced aggression become less plausible as the delay between the initial provocation and the minor triggering event increases because the arousal generated by the initial provocation dissipates. However, by ruminating about a provocation, an aggressive internal state can be maintained over an extended period of time. The 8-hr delay used in Study 3 provides even stronger evidence in support of a ruminatively based explanation of displaced aggression. Any arousal generated by the initial provocation would have dissipated after $8 \mathrm{hr}$.

A second difference between the first two studies and Study 3 concerns the nature of the control conditions. In Study 1, the rumination condition was compared with both distraction and positive mood conditions. Study 2 again compared the rumination condition with a distraction condition. Thus, in both of these studies, the source of the difference between rumination and comparison conditions was ambiguous because of the absence of a true no-treatment control condition. Although we have argued that rumination increases aggression, a plausible alternative interpretation is that distraction (or positive mood) decreases aggression. By contrast, the rumination condition in Study 3 was compared with a true no-treatment control condition. Of course, it is likely that events over the course of the 8-hr interval between the provocation and the trigger may well have been distracting. Nevertheless, participants in the control condition received no explicit instruction or task that functioned to distract them immediately after receipt of the provocation. In this sense, there is no interpretative ambiguity in Study 3 about the source of difference between the rumination and control conditions.

Study 3, which used new operational definitions of provocation, trigger, rumination, and aggression, replicated Studies 1 and 2. This consistency under different operationalizations of the key variables illustrates the robustness of triggered ruminative aggression. 


\section{General Discussion}

The three studies presented here provide evidence for ruminatively based triggered displaced aggression. In all three studies, provoked participants who were induced to ruminate displayed more displaced aggression after a mildly annoying triggering event than did those who did not ruminate. Rumination appears to augment triggered displaced aggression by maintaining an aggressive internal state. A provocation, such as an insult, increases negative affect and primes aggression-related thoughts, feelings, and behavior tendencies. This aggressive internal state, in turn, influences how individuals perceive and react to subsequent events (Berkowitz, 1993; Miller et al., 2003). Thus, a mildly annoying event is perceived as highly aversive and deserving of an aggressive response. If provocation-induced negative affect, however, is allowed to dissipate, the subsequent mildly annoying event is perceived as trivial and is easily dismissed.

The purpose of the current studies was to examine situations in which the temporal gap between an initial provocation and a subsequent triggering event exceeds the $10 \mathrm{~min}$ in which arousalbased explanations of displaced aggression are likely. Typically, negative affective states last approximately $10 \mathrm{~min}$ (Fridhandler \& Averill, 1982; Tyson, 1998). Because previous displacedaggression studies have never extended the time period between the provocation and the trigger beyond $10 \mathrm{~min}$, the persistence of arousal generated by the initial provocation can reasonably explain these empirical findings.

In these three studies, however, triggered displaced-aggression effects were demonstrated over a longer time gap (viz., $25 \mathrm{~min}$ in Study 1, $20 \mathrm{~min}$ in Study 2, and $8 \mathrm{hr}$ in Study 3), making an arousal-based explanation highly unlikely. Under temporal delays of these durations, ruminatively based explanations seem more appropriate. Thus, our studies have an applied significance in that rumination can explain a large number of instances of real-life displaced aggression in which the aggressive act might occur hours after an initial provocation.

Studies 1 and 2 show that ruminating about a provocation maintains an aggressive internal state that disposes an individual toward later displaced aggression. People who ruminate about a provocation experience more negative affect in response to a minor triggering event. Negative affect, in turn, increases aggressive retaliation. These mediational effects, resting on the negative affect produced by the provocation (Study 1) and on negative reactions to the triggering event (Study 2), are consistent with Berkowitz's (1989, 1990, 1993) cognitive neoassociationistic model of aggressive behavior, which posits a key mediational role for negative affect.

Have we fully isolated the key internal state that accounts for the aggression-augmenting effect of rumination? Obviously, we have not. For instance, although the augmented negative reactions to the trigger functioned to mediate the aggression-increasing effect of rumination in Study 2, note that the items comprising this mediational measure appear to tap two distinct dimensions of the GAM - negative affect and hostile attributions. Specifically, two items assessed affect (participants rated how angry the trigger made them and how much it bothered them), whereas the remaining items assessed evaluation-based attributions about the ostensible partner (overly critical, harsh, and nasty). In light of the high alpha among these two sets of items (.88), it made empirical sense to analyze them as a single composite. Note also, however, that high correlations among the conceptually distinct antecedents of aggression are not inconsistent with the GAM. Moreover, as previously indicated, negative affect and negative reactions to the triggering partner are not the only potential mediational variables of interest. As noted, we did not measure other relevant components of the GAM that are also postulated to mediate aggressive responding, such as physiological arousal level and behavioral intentions. Although a thorough analysis of the processes that underlie rumination effects was beyond the scope of this set of experiments, future research on the relation between rumination and aggression will need to address this mediational issue more analytically. Not only might some of the routes to aggression routinely postulated by the GAM be more readily or strongly activated by rumination than others, but different means of inducing rumination might also have distinct effects. For instance, self-focused inductions of rumination (e.g., that used in Study 1), which turn attention inward, might be expected to particularly augment the accessibility of cognitive representations of the physiological arousal induced by an initial provocation. By contrast, provocation-focused inductions of rumination (e.g., that used in Study 3), which give the actor an external orientation, might be expected to particularly augment cognitive representations of imagined or intended aggressive actions toward the provocateur.

\section{The Relationship Between Ruminatively Based Displaced Aggression and Excitation Transfer Theory}

We suggest that the results of the current set of studies are best understood by using a ruminatively based explanation of displaced aggression. One might argue, however, that our theoretical analysis of triggered displaced aggression appears to share general conceptual similarities with excitation transfer theory (Zillmann, 1971, 1979) and that the latter theory can explain our findings. In excitation transfer theory, a provocation is combined with a manipulation of arousal such as noise, an erotic film, or physical exercise (e.g., Cantor, Zillmann, \& Einsiedel, 1978; Donnerstein \& Wilson, 1976; Zillmann, Katcher, \& Milavsky, 1972). ${ }^{4}$ At first glance, such manipulations of arousal correspond in some sense to what we have called a triggering event. According to excitation transfer theory, physiological arousal produced by an event does not dissipate instantly. If two arousing events are separated by a short amount of time, some of the arousal caused by the first event may transfer (or be misattributed) to the second event. For example, if the second event is related to anger, then the additional arousal lingering from the first event (e.g., exercise) should make the person even angrier. The misattribution of arousal may occur because the source of the arousal is ambiguous. Individuals do not realize that the arousal that is generated by the initial event will

\footnotetext{
${ }^{4}$ The manner in which excitation transfer experiments operationalized arousal is as follows (in order of most to least frequent): violent/aggressive films: 24; sexually arousing pictures: 8 ; erotic films: 6 ; erotic passages (written): 5 ; exercise: 4; drugs: 4; sports films: 3 ; noise/tones: 3 ; happy films: 2 ; unpleasant films: 1 ; exciting, nonviolent films: 1 ; hostile news broadcast: 1 ; arousing imagery (imagine a scene): 1 ; aggressive passages: 1 ; and pain cues from target: 1 .
} 
linger and thus assume their aroused state was caused by the second, more proximal, event.

There are four important differences, however, between these two bodies of research. First, excitation transfer studies mainly (if not exclusively) examine direct aggression against the original provocateur, whereas the current studies examined displaced aggression.

Second, the triggering event in our studies was deliberately designed to be trivial and very low in its arousal qualities. By contrast, the erotica or strenuous physical exercise typically used in excitation transfer research characteristically elicits moderate to high levels of arousal.

Third, excitation transfer theory posits that if the source of the physiological arousal generated by the first event is salient, the likelihood of the transfer of that excitation to the second event is unlikely. For example, if an individual exercises vigorously and is then provoked, and believes that the arousal is due to the exercise, the person is unlikely to misattribute the arousal to the provocation. In our Studies 2 and 3, we manipulated rumination by having participants specifically think about the initial provocation, thereby making it highly salient. According to excitation transfer theory, ruminating participants should therefore engage in less displaced aggression because the source of their arousal is highly salient. However, the results of all three studies show the opposite pattern-participants who ruminated about the initial provocation engaged in more displaced aggression than participants who did not ruminate. One might argue instead that both the initial provocation and the subsequent trigger are given the same label by the participant (viz., a provoking event). This argument, however, is not a strong one. The initial provocation and the subsequent triggering event in our studies not only were qualitatively distinct but also were delivered by two separate people who were functioning in two distinct roles. The salience-inducing effect of the rumination induction used in Studies 2 and 3 is only likely to make this distinction even more evident to participants.

Fourth, the current studies investigated situations with a long temporal delay between the provocation and the triggering event. To our knowledge, no excitation transfer studies contain a temporal delay between the provocation and the arousing event that exceeds the 5- or 10-min period for which a state of arousal ordinarily persists. ${ }^{5}$ Thus, we argue that an underlying cognitive process, specifically rumination, is driving the triggered displacedaggression effects.

\section{Limitations and Future Directions}

The current studies, like all studies, have limitations. Some may question whether displaced aggression can accurately be assessed in a laboratory setting. For example, one may question whether giving a negative performance evaluation or blasting a partner with white noise parallels snapping at a coworker or cursing a roommate. Meta-analytic work, however, suggests that most laboratory measures of aggression appear to assess the same underlying construct (Carlson, Marcus-Newhall, \& Miller, 1989). Also, findings from laboratory studies of aggression parallel findings from real-life studies of aggression (Anderson \& Bushman, 1997).

Our results suggest that ruminating about a provocation increases the likelihood of triggered displaced aggression. To facil- itate ruminatively based displaced aggression, we induced participants to engage in internally focused thinking or thought about the provocation. Other situational factors, however, might also influence ruminatively based displaced aggression, such as the strength of the provocation and the importance of the goal the person is blocked from achieving. Another limitation of our three studies is that we did not include any measures of physiological arousal. We argue that with a substantial delay (viz., longer than $20 \mathrm{~min}$ ), arousal directly generated by the initial provocation dissipates before the subsequent triggering event. However, we do not have any physiological data to support such a claim. Moreover, it is possible that ruminating about a provocation might elicit not only cognitive representations of the prior physiological arousal produced by the provocation, but additionally, it might maintain or reinstate the physiological arousal generated by the initial provocation. Alternatively, or additionally, it might induce stronger physiological arousal reactions to the trigger, which, in turn, might increase its aggression-eliciting effects.

Finally, certain personality factors might serve as moderators. There is considerable evidence suggesting that some individuals are more prone to rumination than others and, in turn, are more likely to behave aggressively (e.g., Caprara, 1986; Caprara, Barbaranelli, Colombo, Politi, \& Valerio, 1995; Caprara, Barbaranelli, \& Comrey, 1992; Caprara, Cinanni, \& Mazzotti, 1989; Caprara, Gargaro, Pastorelli, \& Prezza, 1987; Caprara, Mazzotti, Zelli, Coluzzi, \& Renzi, 1985; Collins \& Bell, 1997). However, no studies to date have examined how dispositional rumination is related to triggered displaced aggression. One might hypothesize that individuals already prone to rumination might show heightened displaced aggression when induced to ruminate.

\section{Conclusion}

The three studies presented here support a ruminatively based explanation of triggered displaced aggression. They provide the

\footnotetext{
${ }^{5}$ One excitation transfer study had an 8-day delay between the provocation and the opportunity to aggress (Bryant \& Zillmann, 1979). Physiological arousal from the provocation certainly could not have affected the aggression opportunity in this case. It is important to note, however, that the temporal lag in that experiment does not correspond to the location of the temporal delay in the current set of studies. Consistent with other excitation transfer studies, the delay between the arousing event and the provocation in Bryant and Zillmann's (1979) study was short—less than 5 min. The 8-day delay is between the provocation and the aggression opportunity. In Bryant and Zillmann's study, residual arousal from the first event (exercise?) could have been attributed to the provocation that occurred shortly thereafter. When given the opportunity to aggress against the original provoker 8 days later, participants may have retaliated against that person. This long delayed effect could be due to a ruminative process, such as those described in our studies. Such a conclusion is speculative, however, considering Bryant and Zillmann did not provide data to support such a claim. Our delayed studies do not parallel the delayed paradigm used by Bryant and Zillmann. The delay in the current studies occurred between the initial provocation and the subsequent triggering event. The triggering event was immediately followed by the displaced-aggression opportunity. An excitation transfer explanation seems unlikely because the long delay between the provocation and the triggering event likely dissipated any lingering physiological arousal, especially when the delay was $8 \mathrm{hr}$.
} 
first explicit evidence linking ruminative activity to aggressive behavior, not just angry affect. Moreover, the studies are high in ecological validity. In real life, instances of displaced aggression often occur long after the initial provocation. Our studies clearly show that rumination is a factor that can maintain an aggressive internal state over an extended period of time.

Individuals undoubtedly face many provocations that make them angry. Often, retaliation against the provocateur is not possible. For example, bosses frequently reprimand employees, who passively accept the criticism in order to keep their jobs. Nevertheless, such provocation still makes individuals angry. It can prompt subsequent aggression against someone who is mildly annoying but not highly deserving of an aggressive attack. How individuals focus their attention after a provocation affects how they will behave toward others. If individuals choose to focus on their bad mood and the provocation that elicited it, they may unfairly lash out against innocent others. If, instead, they choose to let their negative mood dissipate and focus on other events, they are less likely to lash out. Rather than "chewing on" the tyrannical boss, perhaps individuals should "chew on" what they want for lunch.

\section{References}

Anderson, C. A., \& Bushman, B. J. (1997). External validity of "trivial" experiments: The case of laboratory aggression. Review of General Psychology, 1, 19-41.

Anderson, C. A., \& Bushman, B. J. (2002). Human aggression. Annual Review of Psychology, 53, 27-51.

Axelrod, R. (1984). The evolution of cooperation. New York: Basic Books. Barnett, V., \& Lewis, T. (1978). Outliers in statistical data. New York: Wiley.

Berkowitz, L. (1989). Frustration-aggression hypothesis: Examination and reformulation. Psychological Bulletin, 106, 79-83.

Berkowitz, L. (1990). On the formation and regulation of anger and aggression: A cognitive-neoassociationistic analysis. American Psychologist, 45, 494-503.

Berkowitz, L. (1993). Aggression: Its causes, consequences, and control. New York: McGraw-Hill.

Bernstein, S., Richardson, D., \& Hammock, G. (1987). Convergent and discriminant validity of the Taylor and Buss measures of physical aggression. Aggressive Behavior, 13, 15-24.

Bryant, J., \& Zillmann, D. (1979). Effect of intensification of annoyance through unrelated residual excitation on substantially delayed hostile behavior. Journal of Experimental Social Psychology, 15, 470-480.

Bushman, B. J. (2002). Does venting anger feed or extinguish the flame? Catharsis, rumination, distraction, anger, and aggressive responding. Personality and Social Psychology Bulletin, 28, 724-731.

Bushman, B. J., \& Anderson, C. A. (2001). Is it time to pull the plug on the hostile versus instrumental aggression dichotomy? Psychological Review, 108, 273-279.

Bushman, B. J., \& Baumeister, R. F. (1998). Threatened egotism, narcissism, self-esteem, and direct and displaced aggression: Does self-love or self-hate lead to violence? Journal of Personality and Social Psychology, 75, 219-229.

Bushman, B. J., Baumeister, R. F., \& Phillips, C. M. (2001). Do people aggress to improve their mood? Catharsis beliefs, affect regulation opportunity, and aggressive responding. Journal of Personality and Social Psychology, 81, 17-32.

Bushman, B. J., Baumeister, R. F., \& Stack, A. D. (1999). Catharsis, aggression, and persuasive influence: Self-fulfilling or self-defeating prophecies? Journal of Personality and Social Psychology, 76, 367-376.
Cacioppo, J. T., \& Petty, R. E. (1981). Social psychological procedures for cognitive response assessment: The thought listing technique. In T. Merluzzi, C. Glass, \& M. Genest (Eds.), Cognitive assessment (pp. 309-342). New York: Guilford Press.

Cantor, J. R., Zillmann, D., \& Einsiedel, E. F. (1978). Female responses to provocation after exposure to aggressive erotic films. Communication Research, 5, 395-411.

Caprara, G. V. (1986). Indications of aggression: The dissipationrumination scale. Personality and Individual Differences, 7, 763-769.

Caprara, G. V., Barbaranelli, C., Colombo, G., Politi, A., \& Valerio, P. (1995). Emotional susceptibility, irritability, and hostile rumination as correlations of coronary heart disease. Personality and Individual Differences, 19, 569-575.

Caprara, G. V., Barbaranelli, C., \& Comrey, A. L. (1992). A personological approach to the study of aggression. Personality and Individual Differences, 13, 77-84.

Caprara, G. V., Cinanni, V., \& Mazzotti, E. (1989). Measuring attitudes towards violence. Personality and Individual Differences, 10, 479-481.

Caprara, G. V., Gargaro, T., Pastorelli, C., \& Prezza, M. (1987). Individual differences and measures of aggression in laboratory studies. Personality and Individual Differences, 8, 885-893.

Caprara, G. V., Mazzotti, E., Zelli, A., Coluzzi, M., \& Renzi, P. (1985). Effect of insult and dissipation-rumination on delayed aggression and hostility. Archivio di Psicologia, Neurologia e Psichiatria, 46, 130-139.

Carlson, M., Marcus-Newhall, A., \& Miller, N. E. (1989). Evidence for a general construct of aggression. Personality and Social Psychology Bulletin, 15, 377-389.

Cohen, J. (1988). Statistical power analysis for the behavioral sciences. Orlando, FL: Academic Press.

Collins, K., \& Bell, R. (1997). Personality and aggression: The dissipationrumination scale. Personality and Individual Differences, 22, 751-755.

Crick, N. R., \& Dodge, K. A. (1994). A review and reformulation of social information-processing mechanisms in children's social adjustment. Psychological Bulletin, 115, 74-101.

de Castro, B. O., Veerman, J. W., Koops, W., Bosch, J. D., \& Monshouwer, H. J. (2002). Hostile attribution of intent and aggressive behavior: A meta-analysis. Child Development, 73, 1467-1486.

Dollard, J. (1938). Hostility and fear in social life. Social Forces, 17, $15-25$.

Dollard, J., Doob, L. W., Miller, N. E., Mowrer, O. H., \& Sears, R. R. (1939). Frustration and aggression. New Haven, CT: Yale University Press.

Donnerstein, E., \& Wilson, D. W. (1976). Effects of noise and perceived control on ongoing and subsequent aggressive behavior. Journal of Personality and Social Psychology, 34, 774-781.

Duncan, B. L. (1976). Differential social perception and attribution of intergroup violence: Testing the lower limit of stereotyping Blacks. Journal of Personality and Social Psychology, 34, 590-598.

Epps, J., \& Kendall, P. C. (1995). Hostile attributional bias in adults. Cognitive Therapy and Research, 19, 159-178.

Fridhandler, B. M., \& Averill, J. R. (1982). Temporal dimensions of anger: An exploration of time and emotion. In J. R. Averill (Ed.), Anger and aggression (pp. 253-280). New York: Springer-Verlag.

Giancola, P. R., \& Zeichner, A. (1995). Construct validity of a competitive reaction time aggression paradigm. Aggressive Behavior, 21, 199-204.

Higgins, E., \& King, G. (1981). Accessibility of social constructs: Information processing consequences of individual and contextual variability. In N. Cantor \& J. Kihlstrom (Eds.), Personality, cognition, and social interaction (pp. 69-122). Hillsdale, NJ: Erlbaum.

Jöreskog, K. G., \& Sörbom, D. (2002). Windows LISREL 8.52. Chicago: Scientific Software.

Konecni, V. J. (1974). Self-arousal, dissipation of anger, and aggression. Personality and Social Psychology Bulletin, 1, 192-194. 
Krauth-Gruber, S., \& Ric, F. (2000). Affect and stereotypic thinking: A test of the mood-and-general-knowledge model. Personality and Social Psychology Bulletin, 26, 1587-1597.

Lieberman, J. D., Solomon, S., Greenberg, J., \& McGregor, H. A. (1999). A hot new measure of aggression: Hot sauce allocation. Aggressive Behavior, 25, 331-348.

Lyubomirsky, S., \& Nolen-Hoeksema, S. (1995). Effects of self-focused rumination on negative thinking and interpersonal problem solving. Journal of Personality and Social Psychology, 69, 176-190.

MacKinnon, D. P., Lockwood, C. M., Hoffman, J. M., West, S. G., \& Sheets, V. (2002). A comparison of methods to test mediation and other intervening variable effects. Psychological Methods, 7, 83-104.

Marcus-Newhall, A., Pedersen, W. C., Carlson, M., \& Miller, N. (2000). Displaced aggression is alive and well: A meta-analytic review. Journal of Personality and Social Psychology, 78, 670-689.

Martin, L. L., \& Tesser, A. (1989). Toward a motivational and structural theory of ruminative thought. In J. S. Uleman \& J. A. Bargh (Eds.), Unintended thought (pp. 306-326). New York: Guilford Press.

Miller, N., \& Baron, R. S. (1973). On measuring counterarguing. Journal for the Theory of Social Behavior, 1, 101-118.

Miller, N., \& Marcus-Newhall, A. (1997). A conceptual analysis of displaced aggression. In R. Ben-Ari \& Y. Rich (Eds.), Enhancing education in heterogeneous schools: Theory and application (pp. 69-108). RamatGan, Israel: Bar-Ilan University Press.

Miller, N., Pedersen, W. C., Earleywine, M., \& Pollock, V. E. (2003). A theoretical model of triggered displaced aggression. Personality and Social Psychology Review, 7, 75-97.

Nowlis, V. (1965). Research with the Mood Adjective Checklist. In S. S. Tompkins \& C. E. Izard (Eds.), Affect, cognition, and personality (pp. 352-389). New York: Springer Publishing Company.

Pedersen, W. C., Gonzales, C., \& Miller, N. (2000). The moderating effect of trivial triggering provocation on displaced aggression. Journal of Personality and Social Psychology, 78, 913-927.
Rusting, C. L., \& Nolen-Hoeksema, S. (1998). Regulating responses to anger: Effects of rumination and distraction on angry mood. Journal of Personality and Social Psychology, 74, 790-803.

Shrout, P. E., \& Fleiss, J. L. (1979). Intraclass correlations: Uses in assessing rater reliability. Psychological Bulletin, 86, 420-428.

Sobel, M. E. (1982). The distribution of independent random variables. SIAM Journal of Applied Mathematics, 14, 511-526.

Taylor, S. P. (1967). Aggressive behavior and physiological arousal as a function of provocation and the tendency to inhibit aggression. Journal of Personality, 35, 297-310.

Tukey, J. W. (1977). Exploratory data analysis. Reading, MA: Addison Wesley.

Tyson, P. D. (1998). Physiological arousal, reactive aggression, and the induction of an incompatible relaxation response. Aggression and Violent Behavior, 3, 143-158.

Vasquez, E. A., Denson, T. F., Pedersen, W. C., Stenstrom, D. M., \& Miller, N. (2005). The moderating effect of trigger intensity on triggered displaced aggression. Journal of Experimental Social Psychology, 41, 61-67.

Wilcox, R. R. (1996). Statistics for the social sciences. San Diego, CA: Academic Press.

Zillmann, D. (1971). Excitation transfer in communication-mediated aggressive behavior. Journal of Experimental Social Psychology, 7, 419434.

Zillmann, D. (1979). Hostility and aggression. Hillsdale, NJ: Erlbaum.

Zillmann, D., Katcher, A. H., \& Milavsky, B. (1972). Excitation transfer from physical exercise to subsequent aggressive behavior. Journal of Experimental Social Psychology, 8, 247-259.

Received May 12, 2004

Revision received November 4, 2004

Accepted November 19, 2004

\section{Instructions to Authors}

For Instructions to Authors, please visit www.apa.org/journals/psp and click on the "Instructions to Authors" link in the Journal Info box on the right. 